\title{
INTERACTIVITY IN MUSEUMS: OPTIONS FOR THE AGA KHAN MUSEUM
}

\author{
by \\ Tihmily Li \\ A Major Research Paper \\ presented to Ryerson University \\ in partial fulfillment of the \\ requirements for the degree of \\ Master of Digital Media \\ in the Program of Digital Media.
}

HBA, Communications, Culture, Information, and Technology, University of Toronto, 2015

Toronto, Ontario, Canada, 2017

CTihmily Li, 2017 


\section{Author's Declaration for Electronic Submission of an MRP}

I hereby declare that I am the sole author of this MRP. This is a true copy of the MRP, including any required final revisions.

I authorize Ryerson University to lend this MRP to other institutions or individuals for the purpose of scholarly research.

I further authorize Ryerson University to reproduce this MRP by photocopying or by other means, in total or in part, at the request of other institutions or individuals for the purpose of scholarly research.

I understand that my MRP may be made electronically available to the public. 


\title{
INTERACTIVITY IN MUSEUMS: OPTIONS FOR THE AGA KHAN MUSEUM
}

Master of Digital Media, 2017

Tihmily Li

Master of Digital Media, Ryerson University

\begin{abstract}
This paper examines the various methods by which digital media is integrated into museum spaces. With the Aga Khan Museum trying to improve the impact and educational outreach of, and engagement with, their permanent collection, digital media can serve as a way to bridge the current gap that exists between visitor knowledge and the information conveyed in the permanent collections gallery. By structuring narratives into the artifacts, a stronger empathetic understanding between visitor and the histories related to these objects is encouraged. Through theoretical research and past case studies, this paper will propose solutions on how digital media could be implemented at the Aga Khan Museum.
\end{abstract}




\section{Acknowledgements}

I would like to personally thank those who helped shaped this journey for me even though the road may have appeared unclear to me at first: staff and faculty of the Master of Digital Media; Master of Digital Media 2016-2017 cohort; Jason Boyd, my supervisor; Michael Carter, my

second reader; Bita Pourvash, Curatorial Assistant at the Aga Khan Museum; the Marketing and Communications team at the Aga Khan Museum; and my friends and family. 


\section{Table of Contents}

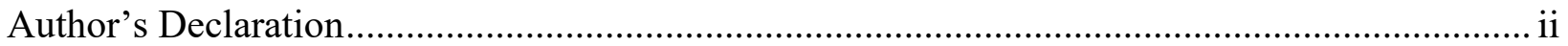

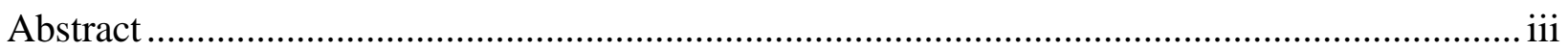

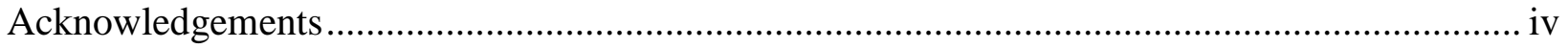

Table of Contents ....................................................................Error! Bookmark not defined.

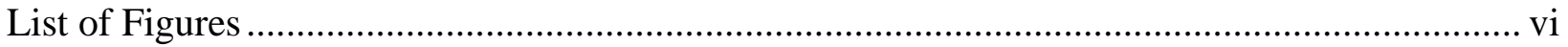

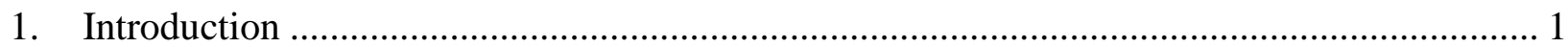

1.1 The Museum's Current Digital Connectivity ......................................................... 2

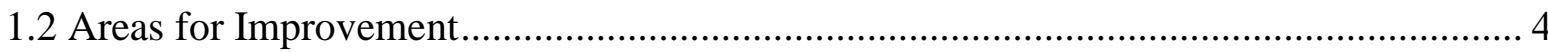

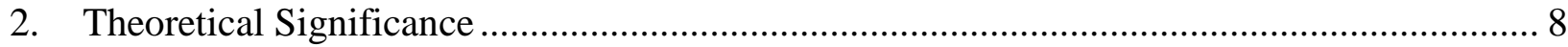

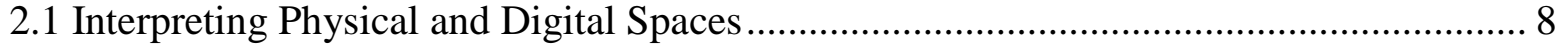

2.2 Narrative Flow: Choice or Structure? ..................................................................... 10

2.3 Utilizing Storytelling in Museum Spaces ......................................................... 12

2.4 Definitions of Success ................................................................................ 14

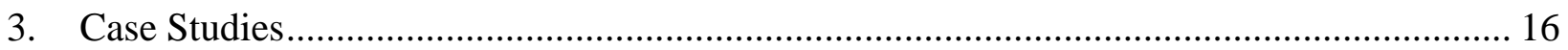

3.1 Use of Personal Digital Assistants (PDAs) .......................................................... 17

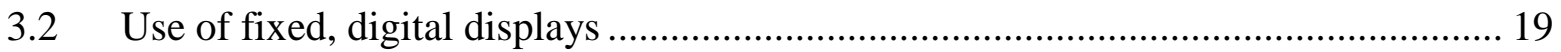

3.3 Use of Mobile Applications.................................................................................. 20

Use of Audio Guides ................................................................................. 23

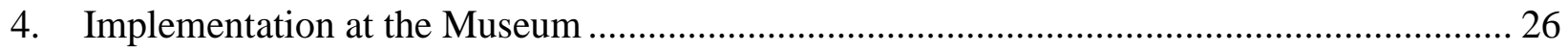

4.1 On-Site Digital Media Implementations............................................................. 27

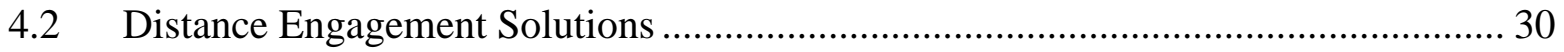

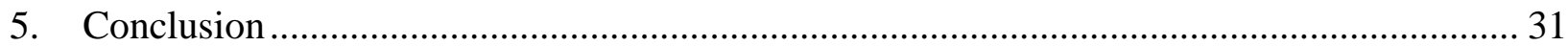

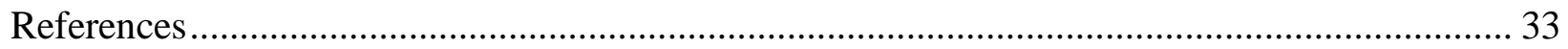




\section{List of Figures}

Figure 1.1 A visitor observes the panoramic video at the temporary exhibition, Syrian Symphony ...... 3

Figure 1.2 Permanent collection's Spain section. ............................................................ 6

Figure 1.3 Permanent collection's Shahnameh (Book of Kings) section.................................... 6

Figure 1.4 Screenshot of the Aga Khan Museum's web content related to this pen box............... 7

Figure 2.1 Identifying the personal and social consequences of using both the museum and the

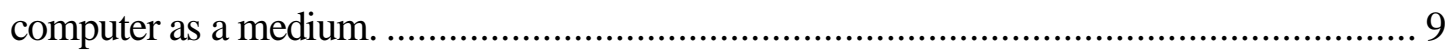

Figure 2.2 The Royal Ontario Museum's Forbidden City exhibition. Photo by Craig Moy. ....... 12

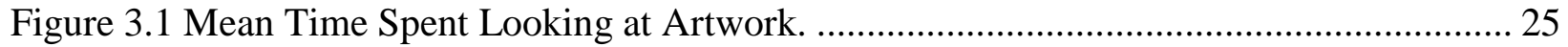

Figure 3.2 Mean Rating on Desire to See More Work by Artist. ........................................... 26

Figure 4.1 Bowls representative of Iranian styles through the ages. ...................................... 29

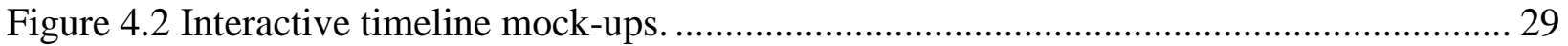




\section{Introduction}

Established in 2014, the Aga Khan Museum is the first museum in North America that is exclusively devoted to Islamic arts and culture. The Aga Khan Museum is a part of the Aga Khan Trust for Culture (AKTC) which is a formal institution under the wider framework of the Aga Khan Development Network (AKDN). Since its opening, the Museum endeavours "to foster greater understanding and appreciation" of Muslim culture through the arts of the Islamic world both historic and contemporary (Aga Khan Museum, 2014). The Museum fulfills this mission through its albeit small but high-quality permanent collection; the curation of temporary exhibitions; guided tours of the Museum's architecture and its exhibitions; in-house performances, lectures, and film screenings; and educational programs for individuals from all walks of life.

Starting in 2017, the Museum will be embarking on a three-year performance contract to measure its impact and its delivery of its main mission. The Aga Khan Museum aims to become a recognized leader in the museum world and develop its reputation as a major museum in Toronto. Most importantly, the Museum wishes to establish a reputation for delivering inspiring, impactful, and accessible content. The guided tours offered at the Museum help to give visitors more context to and insight into the artifacts and artworks they are viewing, but understandably these tours are limited to specific start times. As a result, some visitors, depending on the time they have to spend in the Museum, may end up leaving without attaining a better understanding of Muslim cultures and history they might have wished to acquire.

\footnotetext{
${ }^{1}$ Any text references to "the Museum" is a reference to the Aga Khan Museum itself. Otherwise, lowercased 'museum' references the general concept of a museum.
} 
It is hoped that the proper integration of digital technology within the permanent collection will help to meet the Museum's objective of educating the public and fulfilling its core mission values. An analysis of the institution's current efforts in the digital realm in conjunction with theoretical studies and best practices from case studies will provide the basis to this proposal on how the Aga Khan Museum can create more impactful and educational exhibits.

\subsection{The Museum's Current Digital Connectivity}

The Museum's current efforts in digital connectivity are focused on its web presence and, in a more limited way, its exhibitions. The institution frequently updates its website as well as maintaining active social media accounts on Twitter, Instagram, and Facebook. Many of these posts promote upcoming exhibitions, performances, and events. Combined with marketing efforts, the Museum's visible online presence is steadily gaining a reputation on popular Toronto-centric websites, such as BlogTO or the subthread for Toronto on Reddit.com, as well as international attention. The Aga Khan Museum also publishes videos of performances, lectures, and behind-the-scene details. The plan is to eventually include podcasts as a part of the Museum's digital offerings for informative content. While the Museum is creating a collection of these online educational materials, this section is not a big draw for website visitors. The Museum's digital presence is more focused on encouraging visitors to visit the physical site and attend performances, exhibitions, and lectures in person rather than providing a uniquely crafted experience of the Museum and it collections via the web or other digital technologies.

The Aga Khan Museum in the past offered and currently offers a few modes of digital interactivity as part of the visitor experience. Previously, the Museum offered a five dollar multimedia guide to visitors but this was later discontinued as information became outdated. 
There was also a pilot project that installed tablets in the permanent collection space in order to highlight the details in the collection's folio paintings. The refreshing of tablet content based on the collection's rotation schedule proved too costly and the pilot was discontinued, but this demonstrates a possible avenue to explore in this proposal. In the Museum's current temporary exhibition, Syrian Symphony, visitors can take pictures of themselves using an installed iPad which then displays the image on a digital screen among portraits of newly arrived Syrian families. This example is strictly encapsulated within the temporary exhibition itself and does not extend outwards onto the institution's various social media pages. In the same exhibition, visitors are invited to view a full panoramic video expanding across three walls to make an encapsulated space (see Figure 1.1). While this is more an example of a contemporary art piece presented as a digital media piece rather than of digital media integration, it does demonstrate that the Museum currently embraces digital media as a means for artistic expression. However, the museum still lacks a sustainable strategy to use digital media as a tool for visitor engagement with the collection's objects.

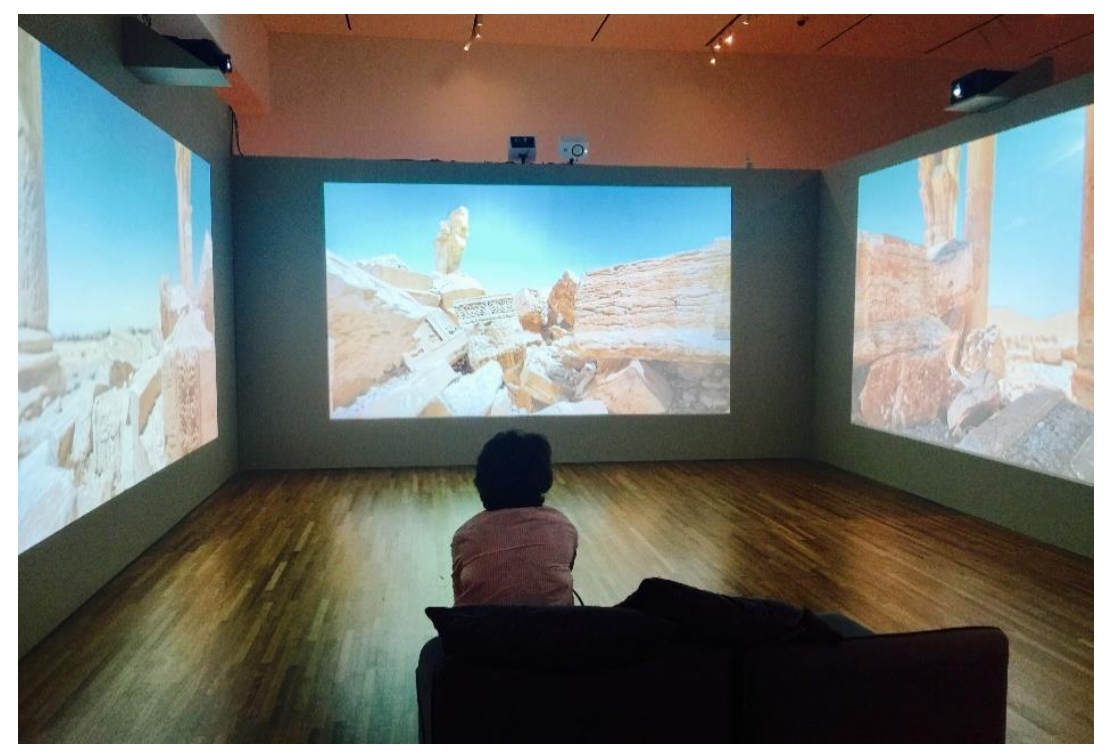

Figure 1.1 A visitor observes the panoramic video at the temporary exhibition, Syrian Symphony. 


\subsection{Areas for Improvement}

There are two aspects of the visitor experience that the Museum can improve upon with digital media. The first area for improvement is the immediate experience of being in the physical space and viewing the permanent collection's objects. Currently the physical setting of the permanent collection provides limited amount of context to the visitor regarding the collection's artifacts. The permanent collection gallery definitely celebrates the objects in a reverential fashion. Display cases are clear and well-lit. Objects are laid out with clear amounts of space around them. Surfaces in the permanent gallery space are predominantly white, though a darker navy is sometimes used to serve as a visual contrast to the white. Text is used sparingly and descriptions are brief. The primary curation focus is to illuminate the objects not only in terms of lighting but also drawing in visitors' attention to them by making them focal points.

The structure and aesthetics of the space can certainly lead to a numinous experience with the objects. A numinous experience allows the visitor to transcend the physical and have a deeply emotional or spiritual connection with an object or site (Wood \& Latham, 2014, p.86). But with the lack of contextual information in the Aga Khan Museum's gallery, the visitor's potential to experience the numinous is limited to the visual. Additionally, if the visitor was expecting to learn something from the displays, the permanent gallery's setup could be detrimental to their experience as there is not enough information to form a coherent understanding of the histories and cultures relating to the artifacts. Even though visitors may want to experience and interpret art of their own accord, they may also appreciate having information conveyed in an organized fashion (Smith \& Tinio, 2008, p. 65). This type of organization is lacking in terms of the layout of objects in the permanent gallery. While there is wall text to highlight key regional information regarding Islamic art, the objects are mixed together from different locations and periods of time 
which can result in confusion. For example, the wall text indicates a time period in Iran but the objects placed in the wall text's immediate proximity are actually from Mughal India. As such, there is a lack of structure in the physical space that results in a breakdown in effectively disseminating contextual information to a visitor.

While the layout of the permanent gallery is generally not structured by region or time period, there are two key examples of good physical space layout. These two examples within the permanent collection are the display of artifacts from Moor-influenced Spain and the collected folios from the Shahnameh (Book of Kings). The area displaying artifacts from Spain is visually distinct in colour and the use of barriers (see Figure 1.2). While this area is not closed off from the rest of the permanent collection, it groups objects in a manner that would suggest to a viewer a relationship between these objects. There is wall text to situate the viewer regarding the context for this area. Similarly, the Shahnameh section also presents a centre display case in a semi-enclosed space with an open book to present the context for the space (see Figure 1.3). Select folios are displayed along the enclosing wall. The experience moving through the space follows the implied trajectory created by the physical layout brings the visitor to view each folio. This space also has music playing overhead which brings a multisensory component to this section. Both of these sections demonstrate an element of narrative flow, whether it is describing Islamic influence in Spain or leading visitors along a narrative through the stories illustrated in the Shahnameh. These examples represent how the Museum can begin to fully utilize physical layout with impactful displays. 

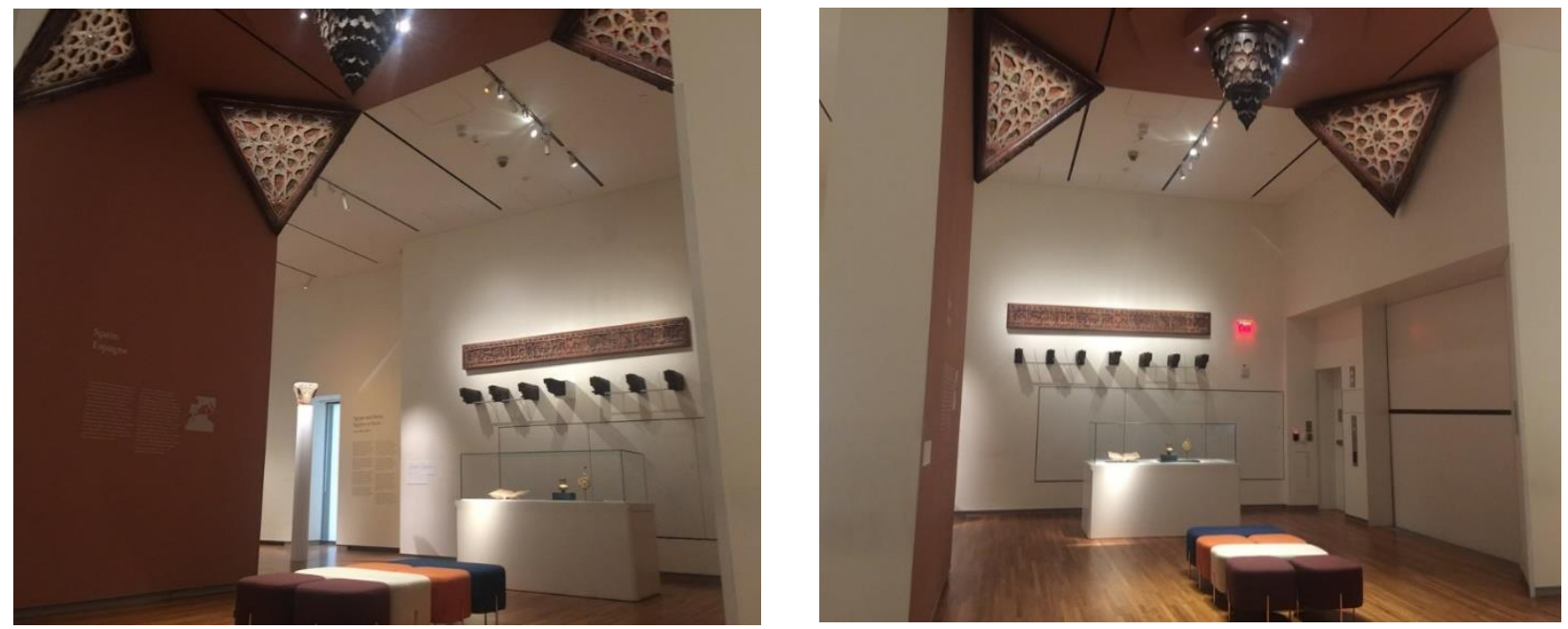

Figure 1.2 Permanent collection's Spain section.
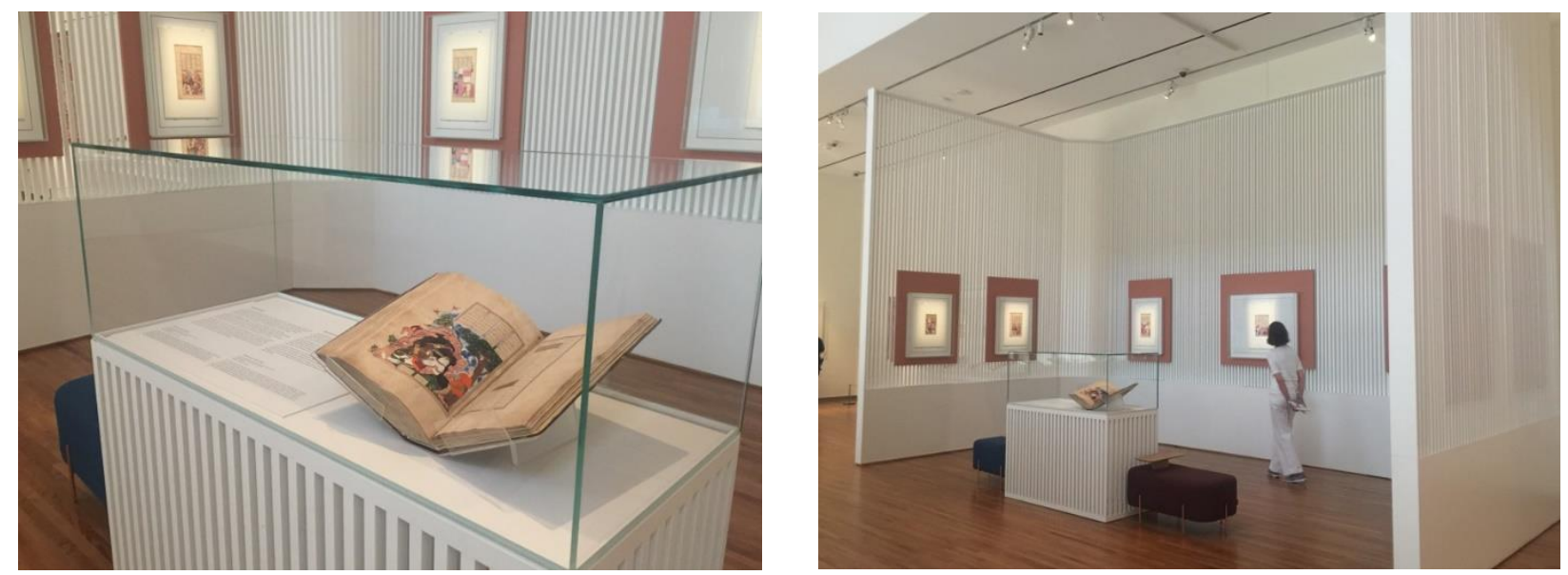

Figure 1.3 Permanent collection's Shahnameh (Book of Kings) section.

The second area for improvement is distance engagement with a visitor or potential visitor. Once a visitor leaves the Museum, there is very little follow-up to provide an extension of the experience. A visitor or potential visitor may choose to follow the Museum's social media accounts, watch videos online, read additional content online, or even list their e-mail for future updates, though it can be argued that the quality of this content is not necessarily the most engaging when it comes to additional materials related to collection items. Take, for example, the website's additional content related to a late $13^{\text {th }}$ century Iranian pen box (see Figure 1.4). 
The webpage provides historical context as to the usage of pen boxes such as this one, but the presence of the object is noticeably missing in comparison to the physical artifact. Rendered in a photograph online, this portrayal of the object lacks the added benefit of materiality that an object situated in a physical space would have. An object's material nature can often be the start of learning in museum settings (Wood \& Latham, 2014, p. 54). Viewing an object in person can better allow visitors to "gain perspective on the relationship between themselves and the object" which in turn affects their perception of the object, its history, and its cultural context (Wood \& Latham, 2014, p. 54). However, digital displays can offer benefits that viewing an object in person cannot. The possibilities in what a visitor can discover about an object could be expanded in a digital medium compared to the limited interaction possibilities of an artifact encased in a display case.

\section{PEN BOX}
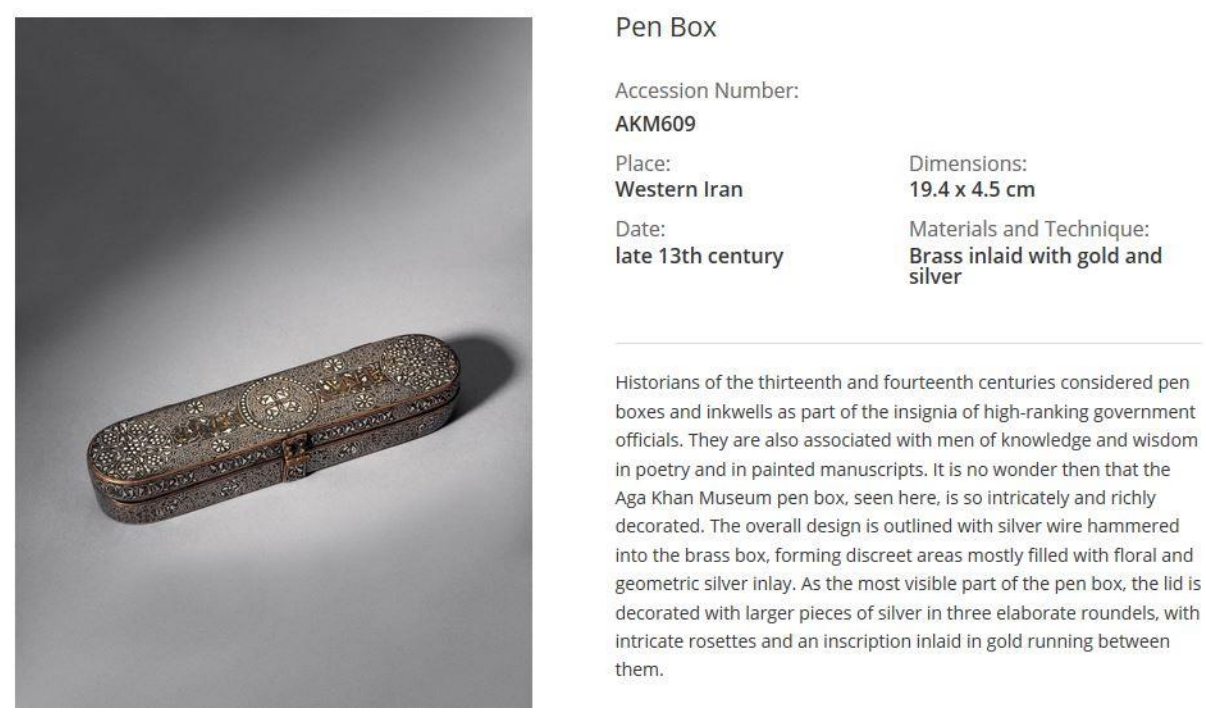

Historians of the thirteenth and fourteenth centuries considered pen boxes and inkwells as part of the insignia of high-ranking government officials. They are also associated with men of knowledge and wisdom in poetry and in painted manuscripts. It is no wonder then that the Aga Khan Museum pen box, seen here, is so intricately and richly decorated. The overall design is outlined with silver wire hammered into the brass box, forming discreet areas mostly filled with floral and geometric silver inlay. As the most visible part of the pen box, the lid is decorated with larger pieces of silver in three elaborate roundels, with intricate rosettes and an inscription inlaid in gold running between them.

Figure 1.4 Screenshot of the Aga Khan Museum's web content related to this pen box. Original page found here: https://www.agakhanmuseum.org/collection/artifact/pen-box-akm609 


\section{Theoretical Significance}

\subsection{Interpreting Physical and Digital Spaces}

There may be a "fundamental incompatibility between the concept of a museum and the concept of a computer" (Parry, 2007, p. 2). However, it would be more useful to view the relationship between digital media and the museum as reciprocal, each affecting and influencing the interpretation of the other (Parry, 2007, p. 5). In contemplating this idea, we must first define the concepts of 'museum' and 'digital media'. A museum can be interpreted as an institution, as a social space, as a repository of history, as a historical piece itself, and as a monument to the culture (or subculture). Through all these interpretations, it can be said that the museum serves as medium for ideas as represented in the collection. For the purposes of this piece examining a specific museum, we shall approach the Aga Khan Museum as a gateway to cultures through history, art, and its physical space.

Similarly, digital media can take many forms and each form can aid in the creation of meaning. Thus, when suggesting digital media solutions for the Museum, we should also take into consideration how meaning is formed and changed through the medium in which it is presented. Already, the visitor's experience is informed by the museum as medium and to add another medium such as digital media will make the meaning formation a two-step process for a visitor (see Figure 2.1). One of the central questions to consider is whether the medium of the museum is incompatible with various digital media. While the meaning of the medium can shift over time, presently museums are considered to be strong arbiters of authority and authenticity and can lend credibility to artifacts, art, and history through its curation. The presentation of space within a museum can also carry certain meanings and these meanings are not always 
neutral. Whether an object is enshrined in a glass case or whether it invites more 'hands-on' interaction communicates different messages regarding an object's value and presence (Parry, 2007, p. 11). By considering "the ideologies and assumptions that are connected with" media both physically present in a museum and digitally available, we can better understand the implications of using digital media and the effect it has upon visitors (Parry, 2007, p. 12). Moreover, it could explain the failings of digital media in museums and the successes in digital media implementation.

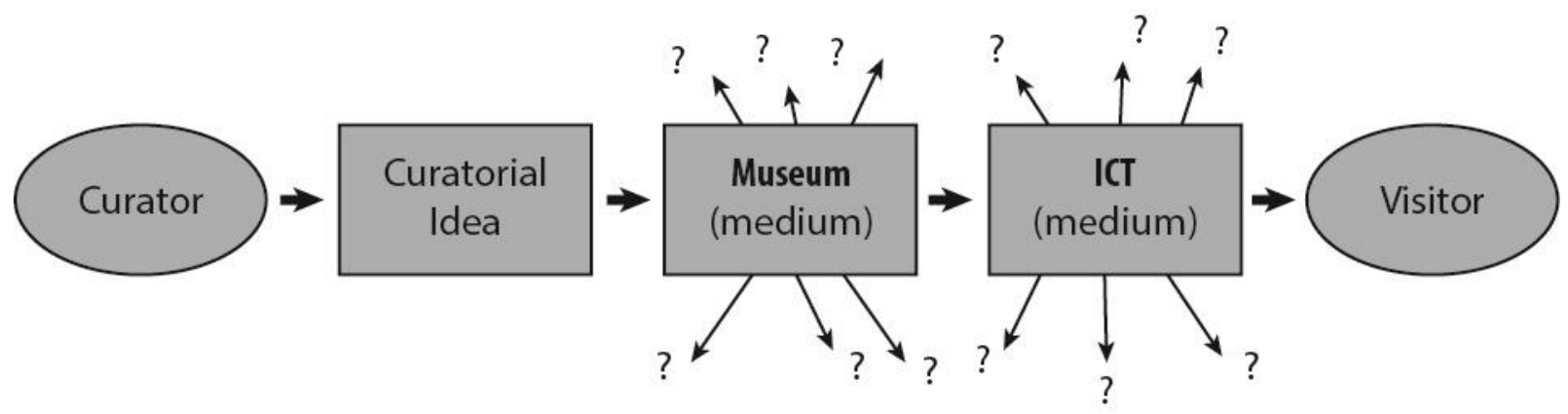

Figure 2.1 Identifying the personal and social consequences of using both the museum and the computer as a medium. Reprinted from Recoding the museum: Digital heritage and the technologies of change, by Ross Parry, 2007. Copyright 2007 by Ross Parry.

Digital media possess some traits that derive from previously existing media. For example, the blog recalls aspects of a personal diary, a bulletin board, a town crier, and even newspapers. However, it is important to understand the unique aspects of digital media. Some distinguishing traits of digital media from other media include digital media's state of being "numerical, modular, automated, variable and transcoded" (Parry, 2007, p. 12). Taking the same example, the blog post is vastly more amenable to edits and revisions, thus making it highly 'variable' in comparison to analog medium's 'fixed' state. While institutions such as museums desire to 
exercise a degree of control over content, brand, and its public image, digital media may introduce an element of unpredictability in how the public engages with these institutions.

This unpredictable element could be tempered in an in-person experience at the museum. By setting limitations and providing structure, these institutions can guide visitors in participating in an appropriate manner. The answer to the question of whether digital media and museums are inherently mismatched becomes more nuanced as elements of constraint and choice are incorporated. As we think about visitor experience being situated in the physical space and how the digital can enhance this, we can begin to come to an understanding that there is no dichotomy that prevents appropriate integration of digital media in a museum.

\subsection{Narrative Flow: Choice or Structure?}

A visitor interested in exploring the museum will “encounter the museum's decisions as to how to present its collections" (Smith \& Tinio, 2008, p. 64). These could run in opposition to the visitor's interest, resulting in a suboptimal experience that does not satisfy the visitor's goals and motivations for visiting the museum. Most museums have to deal with the difficult choice of making curated spaces that tell a specific narrative versus an interactive experience which invites visitors to construct their own narratives. To structure the physical space or a guided tour using an overarching narrative can be beneficial in providing a coherent experience to visitors. However, any deviation from this narrative structure may result in an unsatisfactory experience. Take for example a hypothetical exhibit that gradually presents a scaffolded narrative to the visitor. As the visitor moves through the exhibition space in a linear fashion, each section of the exhibit will build upon the preceding section. If this structure is not adhered to, it would result in a disjointed narrative and potentially make the visit unsatisfactory. The rigid structure of the 
exhibit may be a point of discontent for the visitor. If instead, the exhibit uses narrative structure and exhibition design to allow the visitor some choice in how they discover information, this could lessen the chances that a visitor will feel frustration over being constrained. While this would reduce the museum's control over interpretation, visitors could have the chance to be active participants in building the story. Ideally, if small elements of choice are introduced in a greater narrative structure, then a visitor's desire for "some variability around the presented information" can be balanced with structure (Smith \& Tinio, 2007, p. 65).

While a museum space could be seen as an incompatible location for interactivity, it holds great potential for embedding interactivity into the physical flow of these spaces and collections. The physical makeup of the exhibition space plays a major role in this narrative construction. Is movement through the museum space linear or nonlinear? How much of the space is constructed to funnel visitors down an intended path? How much of the space leaves openings for exploration?

The Royal Ontario Museum (ROM)'s 2014 temporary exhibition, Forbidden City is one local example of the physical space utilized to tell a grander narrative. On the macro level, the entire exhibit was to educate visitors on life behind the walls of China's imperial palace city. The layout of the exhibit gives visitors the freedom to view the various areas of the imperial palace such as the outer courts, the inner courts, and the imperial throne room. The areas were arranged so that those closer to the exhibition's entrance were areas farther from the centre of the palace. As visitors moved inwards, more of the inner court's sections were revealed. This layout, starting from the palace entrance and moving inwards, reproduces a physical journey into the royal grounds. Each small section contained notes and objects that were closely associated with these areas. The different sections of the exhibition meant to correlate with the imperial palace were 
clearly delineated with physical dividers (as can be seen in Figure 2.2). The Forbidden City exhibit restricts entering and exiting from the exhibit to specific areas, most likely to reinforce the careful layout of the exhibit. But by allowing visitors elements of choice within each

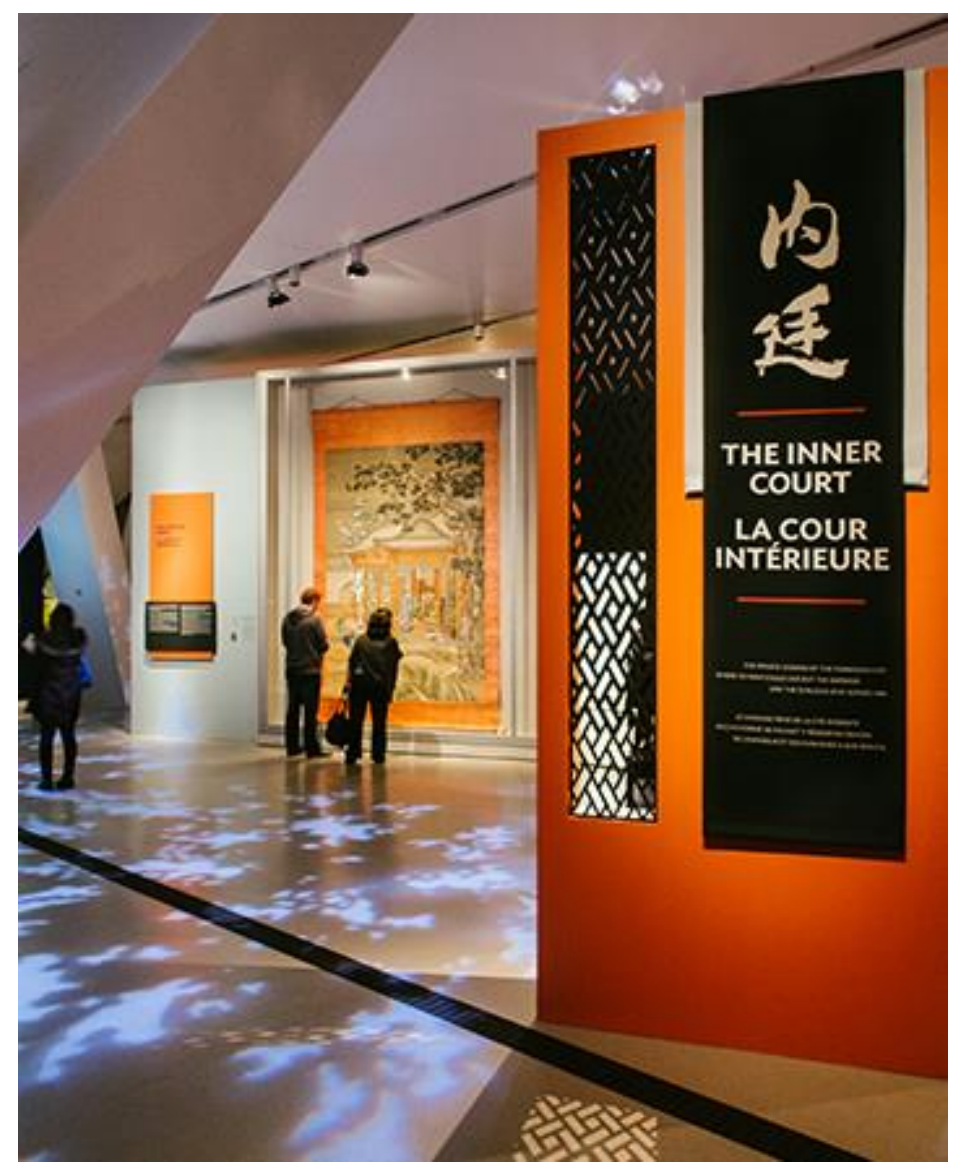

Figure 2.2 The Royal Ontario Museum's Forbidden City exhibition. Photo by Craig Moy. structured area, the overall narrative is presented well without negating a visitor's desire the freedom to explore and interpret.

\subsection{Utilizing Storytelling in Museum Spaces}

After incorporating elements of narrative structure into a museum space, it makes sense to incorporate storytelling into the visiting experience itself. This storytelling element can be easily introduced in guided tours and create "[an] invigorating learning environment" (Museum Hack, 
2015). By weaving a story relating a museum's objects to experiences, the depth of empathy and knowledge regarding the objects histories is increased. Moreover, by incorporating a story with these objects, these objects will then encourage meaning making in a sociocultural context. Being able to situate an object's history in this sociocultural context could allow a visitor to see the object more than just an object on display. Instead, the visitor may recognize the object as having multiple connections to the greater culture or history. Ideally, this may even provoke dialogue about the object in the sociocultural lens amongst visitors in a group. These artifacts and experiences that provoke moments of "socially networked experiences," are then known as social objects (Simon, 2010, p. 127). This type of social interaction will also aid in a visitor's meaning formation. Falk and Dierking (2008) note that visitors "are strongly influenced by the interactions and collaborations they have with individuals within their own social group" (p. 21). By collaborating together through the story of an object, visitors can form new perceptions and understandings of an object.

However, this approach is object oriented and does not examine the piece in relation to other objects or to the space. Storytelling in these spaces should be arranged in a scaffolded structure onto the physical experience of walking through an exhibition and, when correctly applied, this can empower visitors "to co-curate their tour with personal connections" and develop new appreciation for a museum's collection (Syms, 2017). Without proper structure, it may result in the visitor being overwhelmed by information. The scaffolding process is very much a two-way engagement process and it may be difficult to achieve through digital interaction. Regardless, scaffolding a greater narrative that builds upon the previous section without a human tour guide can be done with careful physical space construction and some digital enhancements. 


\subsection{Definitions of Success}

A curator's goals may not be completely aligned with the purposes of impactful engagement with an exhibition. Srinivasan, Becvar, Boast, and Enote (2010) define two paradigms regarding collection objects. The first paradigm is "object as specimen" and this is what is traditionally associated with museology practices (p. 736). The second paradigm understands the object as embedded in "a larger, dynamic cultural, and discursive system" (Srinivasan et al., 2010 p. 736).

Depending on the curatorial goals, either paradigm could serve as a guide for defining success. When an object is removed from its original context, and placed in a distant museum, it is then a representative of its origin and interpreted from the pre-existing knowledge each visitor brings (if any). If curators want to establish their curatorial goals using the object-as-specimen paradigm, then the exhibition subscribes to the idea that the object is a "representation of a larger body of knowledge" (Srinivasan et al., 2010, p. 736). With this paradigm, the objects are not presented as sites giving rise to multiple understandings but rather as loci of absolute knowledge. In contrast, the understanding of an object as an embedded piece allows for the embracing of the idea that there are multiple ways of interpreting a piece (Srinivasan et al., 2010, p. 738). Allowing for diverse understandings is another means to enable social learning and form an empathetic relationship to the object.

The second paradigm supports the goal of producing a more engaging exhibit, as it encourages active meaning formation rather than passive information absorption. Digital media can aid in "situating the experience within the broader context of the lives, the community, and the society" for the visitor (Falk \& Dierking, 2008, p. 27). This embeds the objects not only in the multiplicity of different ontologies, but also in the visitor's world, provoking meaning 
formation in diverse contexts. With effective digital media implemented in the galleries, curators can satisfy the goals of the second paradigm.

Meanwhile, a visitor's expectations and goals may not coincide with the museum's purpose. Depending on a visitor's "prior knowledge, motivation for visiting the museum, or prior interest in the topic of the museum," the expectations may vary (Falk \& Dierking, 2008, p. 25). For a visitor with limited prior knowledge of the museum's subject matter, they may expect a more indepth introduction to the topic. A visitor with more in-depth knowledge of the subject matter may instead require less information but more orientation to the physical space (Falk \& Dierking, 2007, p. 25). Rather than grouping visitors in traditional demographics, such as race, gender, age, etc., it would be more useful to group visitors in terms of their motivations for learning and visiting (Falk \& Dierking, 2007, p. 25). Understanding the needs of visitors through these three categories (prior knowledge, motivation, prior interest) may yield a better understanding on how to meet those needs.

The expectations of a visitor may also change with the type of museum they encounter. A visitor would expect a different method for the display and layout of exhibits and information in an art museum and in a natural history museum. This may be where the Aga Khan Museum suffers in satisfying visitor expectations. The Museum is more or less a cultural hub that showcases art, and thus its presentation may be more similar to an art museum. However, individuals visiting the Museum may expect the institution to be a history museum and thus may see their expectations unmet. By providing scalable experiences, museums can better match the diverse expectations of visitors. 


\section{Case Studies}

This section will summarize previous research upon the effectiveness of digital media implemented in museum spaces. From each method, best practices will be distilled and can be measured against the previous theoretical knowledge from Section 2.

While new technologies can be effective at enhancing participation in museum and gallery collections, there is still some debate around the method of integrating the new technology as part of the aesthetic experience. While digital displays can provide interactive features in art museums, it can be difficult to assess the value of investing time and money into a feature which may not be completely successful. Institutions still grapple with determining value in this context, with an over-reliance on financial benefit. Instead, the focus should be on the development of new assessment techniques for exhibition quality and whether the exhibition design is aligned with core mission values. In the case of the Aga Khan Museum, one of the core mission values is to be a leader in educating the public on Islamic cultures and Islamic art.

While many studies in cognitive science would show that learning can be stimulated through social interaction such as discussion with other visitors, many visitor studies traditionally only focus on the individual experience, rather than the group. The Contextual Model of Learning's sociocultural aspect suggests that a person's meaning making is not only strongly influenced by "individuals within their own social group" but also with quality interactions from others outside their social group (Falk \& Dierking, 2008, p. 21). Activities or technologies that stress the insular (the individual) may be missing out on this key function of learning through sociality. But it should be noted that discussion of their experiences may occur afterwards, outside of the immediate experience and exhibit space. Thus, this could increase their knowledge and 
understanding. This also does not mean that the use of highly personal devices cannot be then used in a collaborative sense.

With a digitally enhanced exhibit, the main goals of the curators are "to increase the amount of time visitors spend with exhibits, to provide visitors with additional information, and to facilitate social interaction and discussion among visitors" (vom Lehn \& Heath, 2005, p. 12). There are some quantitative indicators that help to measure the effectiveness of an exhibition's ability to pass on new knowledge to visitors. Vom Lehn and Heath (2005) describe them as 1) stopping power (how many visitors stop at an exhibit), 2) dwell time (how long does a visitor spend on average at the exhibit), and 3) communication power (how effectively is the information delivered to the visitor) (p. 12). Each of these factors could exist in isolation. An exhibition could cause a visitor to stop and dwell but at the same time lack the communication power to convey information.

\subsection{Use of Personal Digital Assistants (PDAs)}

In vom Lehn \& Heath (2005)'s study, the personal digital assistant (PDA) guide makes use of both visual and audio capabilities to convey information to the viewer. With the PDA, it was immediately observed that the act seems to Displace the Object (vom Lehn \& Heath, 2005, p. 14). Displacing the Object signifies the moment when the visitor "remains oriented to the device ... rather than the art work" (p. 15). This is when a visitor's attention is more fixated on the details being displayed on the device rather than the object itself. This form of digital media enhancement does fulfill the ability to convey information to a visitor (the communication power is high) but this results in attentiveness being directed away from the object. 
While visitors will follow prompts to look at a piece of art when using the audio component, they tend to stand in a stationary position. From vom Lehn and Heath's (2005) description, the discovery and experience moving through the space is hampered through the use of this device. There is also a disruption in the regular ebb and flow of movement through the space for others as individuals using the PDA and headphones are not as aware of others in their vicinity. This makes viewing some artworks difficult for others or discourages them to 'dwell' at a piece due to another person occupying the space. This usually would not occur if an individual is more cognisant of others in their vicinity. Typically, individuals would make space to allow for others to view the artwork but using the PDA device causes the visitors to become "desensitized to their immediate environment" (p. 16).

The use of a PDA device can serve as a great method of structuring a museum visit and thus can serve as a method for constructing narrative understanding. However, this method could result in a visitor feeling unfulfilled in terms of social interaction. While handheld devices need not subject their users to a socially isolated experience, the conventional method of implementing PDA devices often results in this very situation. As users are required to focus their attentions on small screens and listen to audio clips through headphones, they will encounter difficulties in engaging in discussion. The experience becomes more of an isolated, individual activity rather than an experience for developing broader meanings. With the use of audio, the delivery of information was not also designed to be interrupted in order to accommodate discussion (vom Lehn \& Heath, 2005, p. 15). The best use case for this form of digital media can be a scalable factor. For individuals who are more focused on gaining an indepth knowledge about the exhibit (individuals with low prior-knowledge but high prior-interest and motivation), a more insular and guided experience could benefit them. The digital media 
may be reconfigured for a pair of individuals or a group by using a shared device or devices to encourage discussion.

\subsection{Use of fixed, digital displays}

Another example that vom Lehn and Heath (2005) examined was an information kiosk that played a 2-minute video to give more information about an art piece, as well as information about connected, interrelated objects. The video would play after being triggered by touch. In an emptier gallery, a visitor may be able to regard the piece, fully watch the video, then reexamine the piece through with an enhanced understanding. However, in a more crowded gallery, many individuals will most likely not watch the video if there is a queue developing or if others are already presently blocking the view.

Again, visitors using this method also tend to examine the supplementary content with greater attentiveness than the actual art piece in question. These fixed digital displays do "not necessarily encourage people to examine the piece in detail” (vom Lehn \& Heath, 2005, p. 17). This could be contrasted with how visitors view conventional labels and gallery cards as resources. Efforts to both examine the object while also watching the film on the display soon results in attention becoming fractured by this division of attention (p. 17). The video will keep playing while the visitor's attention is affixed to the object and thus some visual information in the video is lost, or the visitor decides instead to focus on the video, relinquishing their attention on the object.

With this method, visitors become a collective audience and the mutual sharing and discussion regarding the object is limited to a few spare comments during the video. Some discussion may occur afterwards but this is highly dependent on whether the subjects wish to 
continue discussing the video. Video, as a medium, is also a highly directed experience. Even with virtual reality (VR) and 360-degree video capabilities broadening the viewer's ability to determine their frame of view, video is still directed at an audience rather than encouraging participation with visitors. A film does not serve as a subservient addition to an object but rather as a dominant feature that renders visitors as passive participants to the overall experience (vom Lehn \& Heath, 2005, p. 18).

Some modifications could be made to increase the social aspect of this technology in order to encourage more social interaction (vom Lehn \& Heath, 2005, p. 19). A possible avenue for developing a better display option would be to use display technology that allows for multiparty participation through multi-touch sensory faculties. This would help facilitate sharing and coparticipation amongst visitors. With the advent of curved screens or larger screens, more individuals can view video footage at once and from many angles. The physical space could also be restructured to improve the foot traffic flow so that individuals can examine the object and then move onwards to examining the information delivered by the video. Lastly, having content that can stimulate discussion would be useful, as it would not only increase the amount of social meaning formation done by visitors, but also improve word of mouth regarding exhibit quality.

\subsection{Use of Mobile Applications}

Mobile applications in museums have found a wide range of uses. They can serve as customization tools for the visit, act as wayfinding and navigational tools, bookmark important information or spaces, and incorporate social media (Tsai \& Sung, 2012, p. 95). As augmented reality (AR) becomes more readily available on smartphones, new possibilities could arise with depicting space and objects through AR. Physical spaces could be transformed through AR to 
allow for visitor interaction thus extending the level of engagement to the physical space itself. AR can further "provide interaction with objects that otherwise would not be possible" and bring a new perspective to how visitors understand themselves in relation to the pieces (p. 96).

The mixed reality capabilities of smartphones can also lead to museum visits to becoming games that encourage exploration. Games on mobile phones can be used by visitors to mediate the physical space and collection items which can provide an unconventional means to encounter and interpret objects. By gamifying the museum, not only could the application engage visitors with finding objects, boost collaboration, but it can also encourage the physical exploration of parts of the museum that are less visited. Though it could be argued that since the objective of these games is focused on "locating rather than interacting with the exhibits" these types of mobile games do not necessarily result in deeper thinking or thoughtful inquiry (Tsai \& Sung, 2012, p. 97). However, this is more of a critique of scavenger hunt-style mobile game design than an outright dismissal of mobile games as a method for engagement in museums. An example of a more meaningful scavenger-type activity is the Smithsonian's Ghost of a Chance game.

The Smithsonian had invited these similar elements of play and exploration in Ghosts of a Chance. Using a mystery story as the narrative framework, the Smithsonian prompts members to investigate the Luce Foundation Center, which is akin to a storage facility that "displays more than thirty-five hundred pieces of American art [...] in densely packed floor-to-ceiling glass cases", and each member would pick out art pieces based on their interpretation of the clues (McGonigal, 2011, p. 174). By completing each part of the mystery, the art piece would then be displayed prominently in a temporary Smithsonian exhibit. In Ghosts of a Chance, members were able to not only explore stored-away art but also collaborate on the stories behind each 
piece of art and contribute to the institution. Ghost of a Chance demonstrates how the collaborative nature of games can transform museum spaces into "spaces of meaningful social participation” (McGonigal, 2011, p. 177). Using a gamified approach, smartphone applications introduce key concepts of social learning to museums.

With such diverse uses for mobile applications, it can be difficult to pinpoint a 'typical' mobile application experience in a museum and to summarize it neatly. A mobile application could be designed either for scalability, niche purposes, or primarily as a customization tool for navigating and experiencing the museum. Scalability once again could refer to anticipating differing needs of visitors based on their prior interest, prior knowledge, and motivations for visiting the museum. For example, the application could be scaled to suit a family outing or individual purposes. Designing for niche purposes could mean focusing on creating a mobile application intended for one purpose which could save on development and roll-out costs. Finally, the mobile application could be designed solely for navigating and customizing a visitor's path through the exhibits.

Mobile tools used in a museum setting can help facilitate activities based around “exploration, information search, communication and experiencing documenting" (Charitonos, Blake, Scanlon, \& Jones, 2012, p. 805). As mobile phones are ever present with the user, the uniqueness of a mobile phone in comparison to a museum-loaned multimedia guide is that a mobile phone has the potential "to support the post-visit experience" (Charitonos et al., 2012, p. 805). Instead of perceiving these mobile applications as a tool for interacting only within a museum, these mobile applications could build the visitor experience from pre-visit, to the visit, to the post-visit follow-up. 


\subsection{Use of Audio Guides}

Audio tours may be seen as more preferred modes of interpretation over person-led tours or textual information as they can give the visitor freedom to choose the "the type and depth of information" (Smith \& Tinio, 2008, p. 65). Compared to data collected regarding person-led tours, it appears as though audio tours do not significantly hinder visitor interaction. Smith and Tinio (2008) observed that out of 30 visitors in a group tour, only 3 asked the tour guide a question and only one interacted with other members of the tour (p. 66). This suggests that the baseline for visitor to visitor interaction is low in a collection of random individuals. Although the sample size was small, the results do match results from a survey regarding the Metropolitan Museum of Art audio tour. Out of the 109 participants that indicated they would normally not use an audio tour, only 4 responded that it was because the audio tour made it difficult to talk to other people (p. 69). Whether these visitors recognized the role of interpersonal communication, or if they simply talked louder to communicate with others, it was not discerned.

There lies a risk in preparing audio tours that certain pieces may be overemphasized to the neglect of others, which would cause an imbalance in the knowledge gained (Smith \& Tinio, 2008, p. 66). Additionally, the visitor may not be able to form their own conclusions about a specific piece of art, relying instead on the interpretations provided from the audio tour. Moreover, audio tours could also impact the visitor flow through a gallery. A linear and limited audio tour would "influence the choices that visitors make regarding what objects to look at" causing a disproportionate time spent at the narrated objects instead of the ones with no audio recorded, whereas a more extensive audio tour would give visitors freedom of choice about which piece to look at next (p. 67). Although, the more extensive the audio tour is, the costlier it would be for the museum to produce. 
A study at the Whitney Museum on their audio tours reveals an interesting correlation between the use of an audio tour and a desire to view more work by the same artist. Twenty visitors completed surveys after experiencing four works of art: George Bellow's Dempsey and Firpo; Arshile Gorky's The Artist and His Mother; Yayoi Kusama's Accumulation; and Chris Burden's America's Darker Moments (Smith \& Tinio, 2008, p. 72). The visitors were separated into three groups that received differing information about these works. The first group had only the standard label, consisting of "title, artist, date, and time of acquisition" (p. 72). The second group experienced the pieces with a special label containing "art historical and stylistic information" (p. 72). The third group experienced the pieces through an audio interpretation.

The audio tours were recorded in different fashions for each work. A sports announcer described Bellow's work given its portrayal of a boxing match (Smith \& Tinio, 2008, p. 72). For Gorky's work, a sociologist discussed the artist's refugee status (p. 72). A clinical psychologist discussed Kusama's work in the context of the artist's experience with obsessive-compulsive disorder (p. 72). Finally, Burden himself talked about his art piece which "is a sculpture split into five pieces that represent events in American history" (p. 73).

First, as we can see in Figure 3.1, with audio tours, the dwell time each visitor spent at each artwork increased. Time spent at the Burden piece was the most across the three groups but the amount of time sharply increases for the audio tour, probably due to the length. Overall, Smith and Tinio (2008) note that since participants were aware that they were in a study, this seems to have led to higher dwell times across all three groups even for a standard label (p. 74). When individuals were also surveyed about whether they would like to see other works by the same artist, the results first show a correlation between time spent and interest, although for Kusama's work, there is the largest gap between those in the first two groups and group 3 despite her work 
being largely inaccessible (see figure 3.2). This instead suggests that "the engaging and revealing nature of the audio stops" were largely the cause for increased interest in Kusama's work (p. 75).

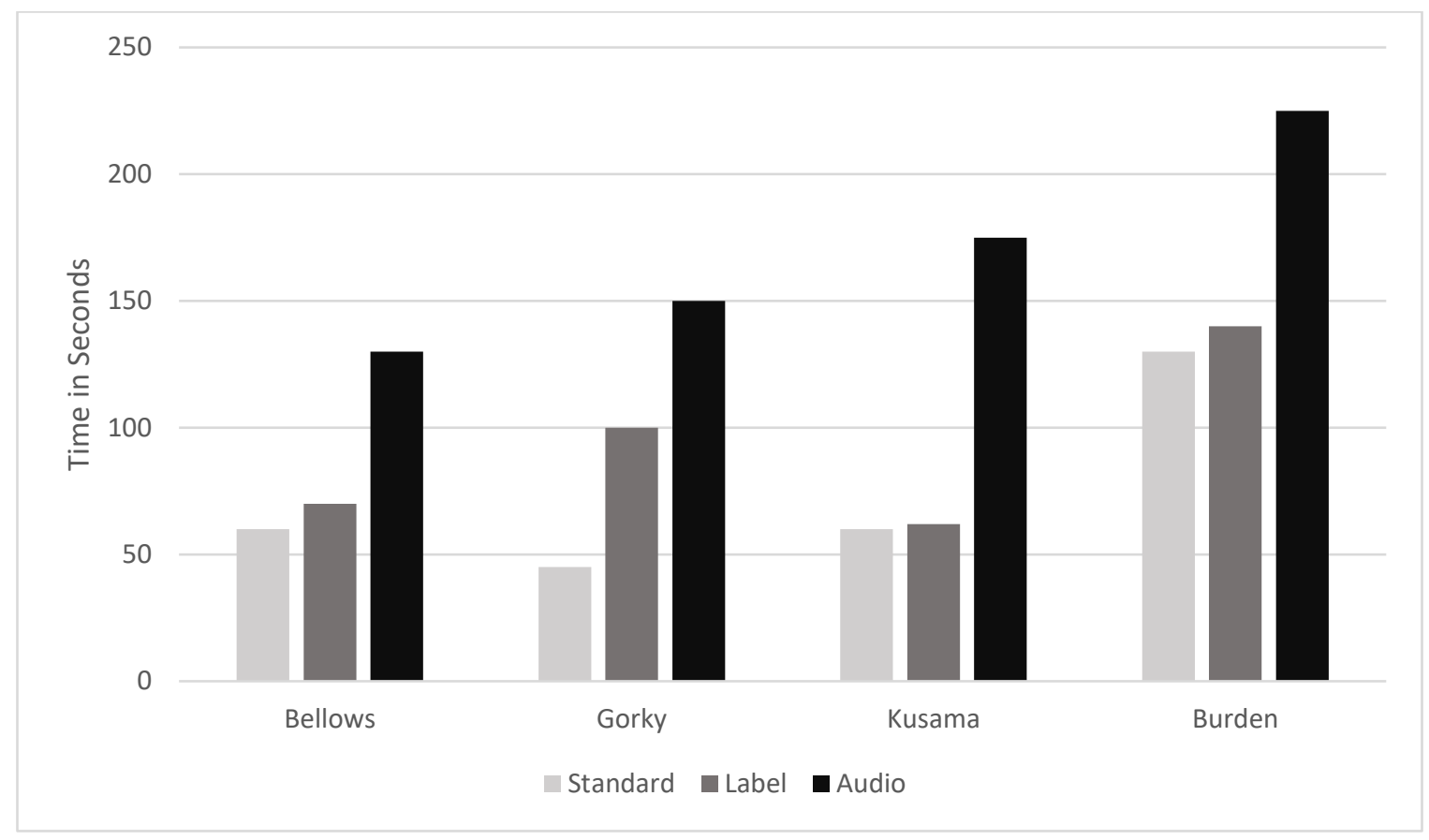

Figure 3.1 Mean Time Spent Looking at Artwork. Reprinted from Audibly engaged: Talking the walk in Digital technologies and the museum experience: Handheld guides and other media, by L. Tallon \& K. Walker (Eds.), 2008. Copyright 2008 by AltaMira Press. 


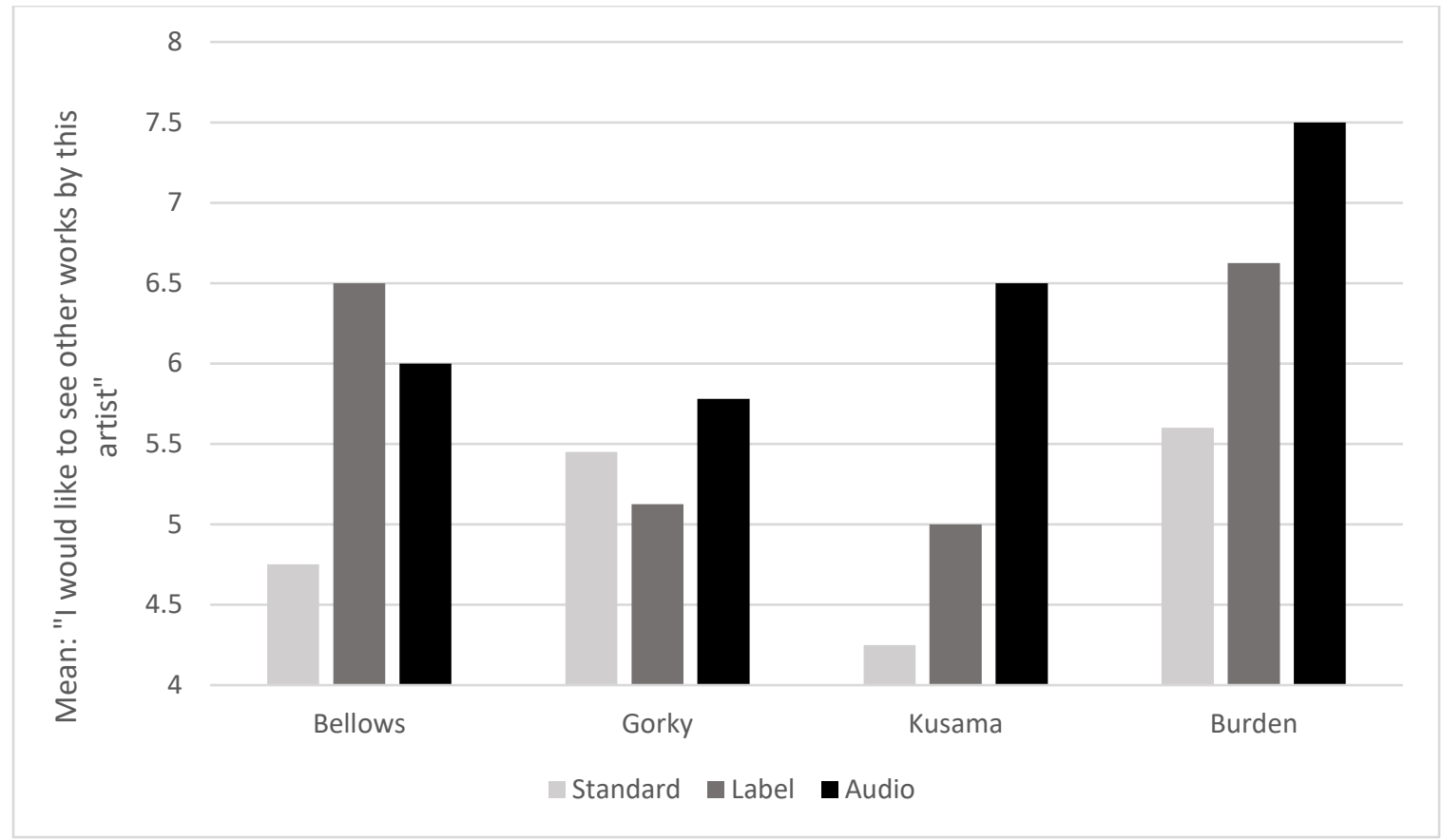

Figure 3.2 Mean Rating on Desire to See More Work by Artist. Reprinted from Audibly engaged: Talking the walk in Digital technologies and the museum experience: Handheld guides and other media, by L. Tallon \& K. Walker (Eds.), 2008. Copyright 2008 by AltaMira Press.

\section{Implementation at the Museum}

As the Aga Khan Museum's mission is "to spark dialogue between cultures through art," the exhibits' goal should be to encourage communication and interaction amongst visitors in order to create a more impactful learning experience (Aga Khan Museum, 2017c, p. 3). In regards to fulfilling the Museum's mission, digital media should be implemented to create scenarios that would invite sociality and conversation. Not only would this give impetus for dialogue, but it would also support complex meaning formation and portrayals of objects as embedded within a greater social context rather than as specimens. Methods that encourage social learning experiences grant a more rewarding visiting experience than those that lack social interactivity. 


\subsection{On-Site Digital Media Implementations}

For a readymade solution, I would recommend utilizing OJOO, an online tool that allows museums to create mobile applications for their museums. The mobile app could allow for the creation of: virtual tours; art guides; museum games; audio tours; and interactive museum plans (OJOO). Not only does this create a diverse app that can serve multiple purposes within the Museum (thus meeting diverse visitor expectations), but its functionality as an art guide and as a virtual tour can serve to strengthen the Museum's connection with members outside of the Museum space. This could be scalable to tablets at Visitor Services should guests not have access to a smartphone. Otherwise, the hardware costs for initial set-up is modest as visitors can be expected to have their own smartphones. This ready-made option for software by OJOO negates cost concerns regarding developing for both iOS and Android. However, the distribution process for a native app must overcome several steps before it is ready to be used. These necessary steps to download a native app involve navigating a phone screen to access the app store, searching for the app, selecting the right search result, installing the app, waiting for the download, and then finally launching the app. Between the first step and the final step in this initial setup process, "every step loses $20 \%$ of potential users" (Dascalescu, 2016, para. 14). As native mobile applications have a high friction distribution, this usage may be more suitable for dedicated tour groups or school classes where a specific type of engagement may be anticipated.

As previously outlined in section 1.2, there is an issue with a lack of context concerning the Museum's permanent gallery. Currently the gallery boasts of objects that fall into seven distinct categories: manuscripts; paintings; metal work; ceramics; tapestries; clothing; and architectural ornamentation. Of this diverse collection of mediums, there is little description of the art styles 
that permeated each geographic region and time period. Here I will present an option for providing contextual information regarding pieces of art in an engaging fashion.

In the permanent collections' space, it has been determined that the wall text is out of place since the overall exhibit has shifted its layout while the wall text remains in place. While the wall text provides a great amount of information regarding each region and time period (specifically for Iran), the information is relegated to only text. There are not any added details that help to connect the knowledge to a visitor's world or previous experiences. My proposal is a large interactive screen that is situated in the exhibit to provide more contextual details about what influenced the art styles in that region. The display must contend with not only depicting a timescale, but also geographic information and information regarding different ceramic techniques.

For example, the Museum has a substantial collection of artifacts from Iran. Across time periods, the style and methods of creating bowls has evolved due to new techniques being discovered or borrowed and also to new materials being traded through the region. As can be seen in Figure 4.1, art styles vary within the same region at the same time as well. The leftmost bowl (AKM740) was created in $10^{\text {th }}$ century Nishapur Iran and is representative of the splashware technique. The bowl second from the left (AKM753) was also created in the same region and time period and is representative of buffware. However, the AKM753 artifact demonstrates "a survival of ancient Iranian motifs" prior to the introduction of Islam to the region, whereas AKM740 represents more abstract patterning (Aga Khan Museum, 2017a). The third from the left (AKM786) represents $14^{\text {th }}$ century fritware techniques while the third from the right (AKM557) is a $13^{\text {th }}$ century lustre painted bowl. Finally, second from the right (AKM691) represents a style of depiction that was more figurative than abstract in the $17^{\text {th }}$ century whereas 
the rightmost bowl (AKM588) represents how Chinese influence in Iran led to Iranian pieces made to resemble Chinese Ming porcelains (Aga Khan Museum, 2017b).

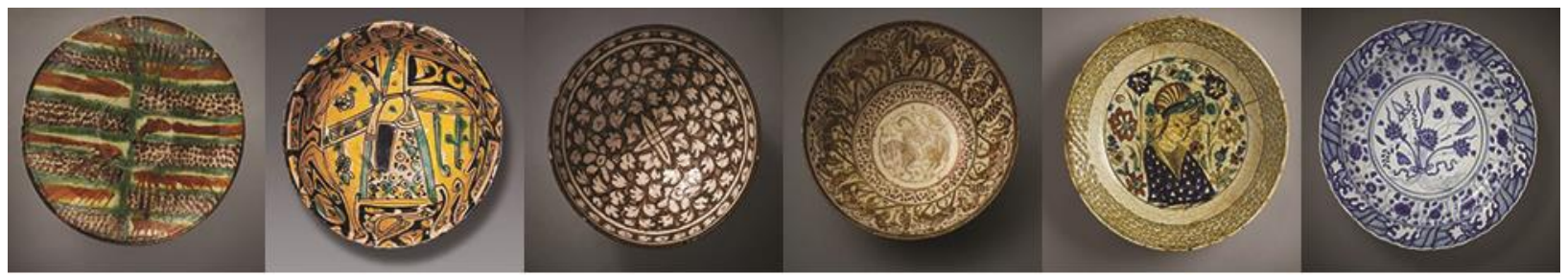

Figure 4.2 Bowls representative of Iranian styles through the ages.
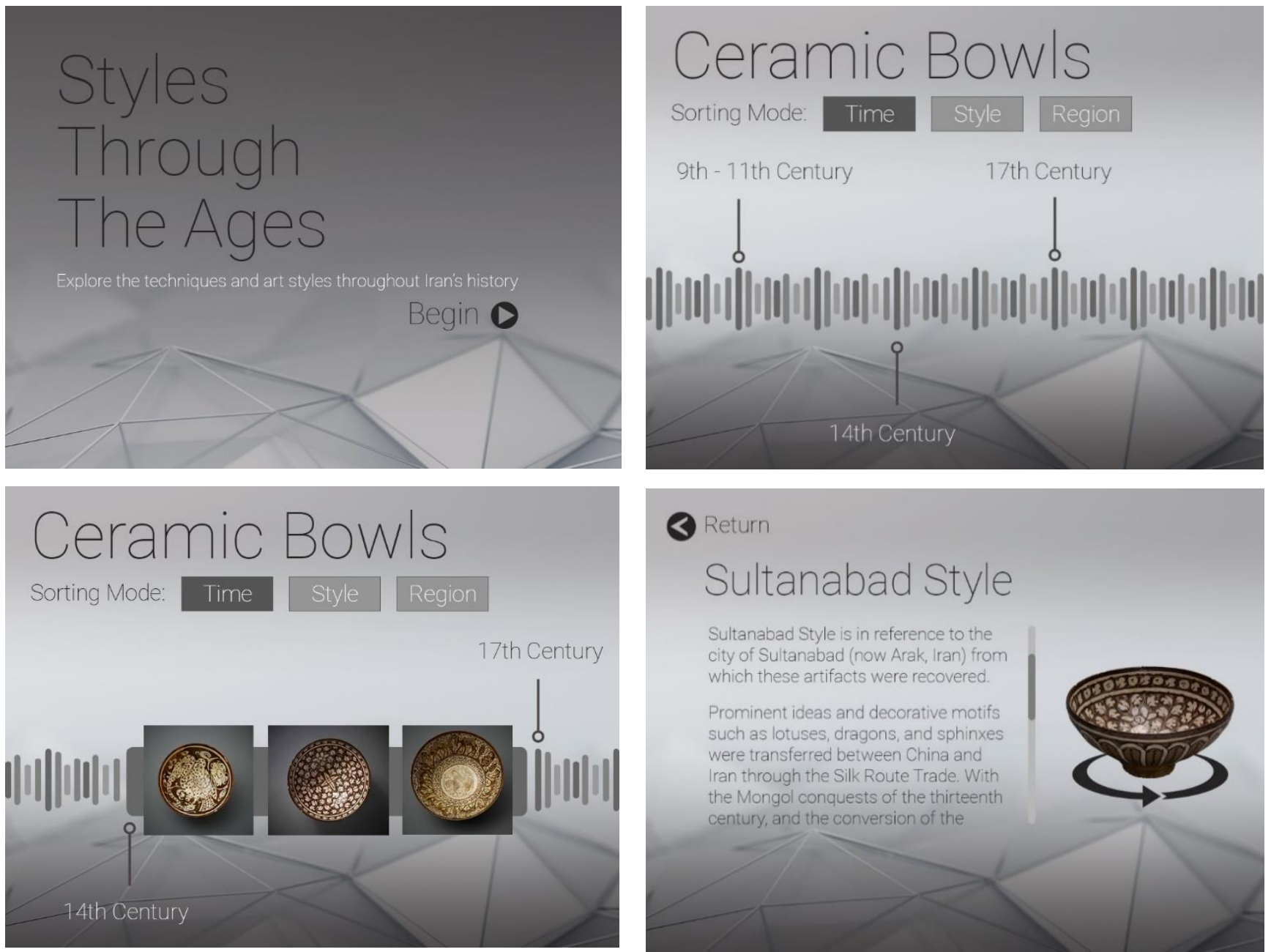

$<$ Return

Sultanabad Style

Sultanabad Style is in reference to the city of Sultanabad (now Arak, Iran) from which these artifacts were recovered.

Prominent ideas and decorative motifs such as lotuses, dragons, and sphinxes were transferred between China and Iran through the Silk Route Trade. With the Mongol conquests of the thirteenth century, and the conversion of the

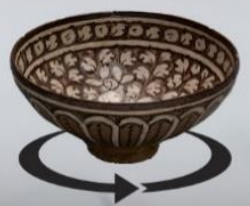

Figure 4.1 Interactive timeline mock-ups.

Despite the rich and varied history of Iranian art, the history is displayed in a manner that mystifies and obscures the narrative story from visitors. This is a present concern in how the 
museum may be able to convey information in a more democratized form. With "the orderliness of presentation and smoothness of display in exhibitions", there is little room for conversation, observations and acknowledgement for the process of interpreting the knowledge from these artifacts (Srinivasan et al., 2010, p. 742). Arguably, by presenting information in a more readily accessible and salient form to the (Western-educated) public, such as an interactive timeline, this would give visitors the contextual grounding to begin framing this new knowledge regarding Islamic art and cultures. As seen in Figure 4.2, a mock-up of the timeline can also recontextualize understandings of artifacts in terms of time, place, and style. For use within the Museum, this type of interactivity would preferably be presented on large interactive screens in order to allow groups to converse and form meanings with each other. This mock-up can also be scaled to personal, private use on a tablet away from the Museum.

\subsection{Distance Engagement Solutions}

The San Francisco Museum of Modern Art (SFMOMA) recently unveiled a new method for individuals to engage with their artworks. As a way to for the rest of their artworks to gain some interaction, SFMOMA has unveiled a texting service called "Send Me SFMOMA" which will deliver "an artwork to your phone based on a sent emoji or phrase" (Sierzputowski, 2017, para. 1). For a collection the size of SFMOMA, it can be quite time consuming to tag related words, phrases, and emojis to a given artwork. While the Aga Khan Museum's permanent collection is not as vast as SFMOMA's, the permanent collection does rotate out objects on a quarterly basis for new objects out of the collection. Some visitors may not be able to see some objects. An added benefit to a smaller collection is that more effort could be allocated to detailing the entirety of the Museum's collection. This particular form of distance engagement through collection items also brings a highly shareable moment through social media. 
Another method of distance engagement is through AR colouring books. The colouring book, "Disney Color and Play" utilizes AR technology to build characters from colouring pages "based on algorithms that interpret the colored lines" (Fessenden, 2015, para. 3). This type of exercise provides a great bonding moment for parents with their children. Applied to the Aga Khan Museum's collection, the colouring books could instead detail folio paintings from the Shahnameh (Book of Kings) to animate the painted scenes and give life to the book. While an illustrated book combined with AR could also be accomplished, the participatory act in colouring the scenes provide a more engaging action than watching a scene unfold without user input.

\section{Conclusion}

A recommendation for the Museum would be to target the previously identified areas for improvements: on-site engagement and distance engagement. As stated in Section 1.2, the content delivery in the permanent gallery may not meet some visitors' goals to educate themselves on the diversity and histories of Islamic cultures. On-site engagement can be enhanced with large interactive screens in the permanent collection to give historical and stylistic context through an interactive timeline. By using large screens, more individuals can view it simultaneously and this could promote social meaning formation among the group. This timeline does not have to reflect the objects currently on rotation in the gallery but are meant as a general representative of the style that emerged within a given geographic area and time period. Previous attempts to keep digital media in the gallery suffered from frequent content updates which eventually became too costly to upkeep. With this suggested approach for the timeline, the need to constantly update the screens and timeline is greatly lessened. Moreover, this timeline could also be scaled to a distance engagement teaching tool to fit on a browser. Future updates to this 
timeline could involve more interactive quizzes and games that can be played in the gallery space or at home.

Interactivity in museums has long been embraced and experimented within the institutions. But in their rush to remain relevant and on topic in the increasingly digital and interconnected world, could these institutions be forgetting the how the physical presence of a museum could also bring engagement? The Contextual Model of Learning posits that meaning making is partly due to the physical setting (Falk \& Dierking, 2008, p. 22). The physical setting here could involve the architecture, layout, colour, space, technology, object labels, and more. Instead of opposing digital media with the museum's space and structure, it would be beneficial to incorporate digital media as an enhancement to the space. Digital media can aid in directing a visitor's trip to the exhibit thus creating better visitor flow, whether it is through handheld devices, audio tours or a mobile application. Digital media can increase a visitor engagement by providing the means to contextualize information given by an exhibit. And lastly, digital media in these museum spaces can provide opportunities for individuals to make human connections not only with the objects on display but with people, both past and present. 


\section{References}

The Aga Khan Museum. (2014). Mission. Retrieved from https://www.agakhanmuseum.org/about/mission

The Aga Khan Museum. (2017a, January). Bowl. Retrieved from https://www.agakhanmuseum.org/collection/artifact/bowl

The Aga Khan Museum. (2017b, January). Dish. Retrieved from https://www.agakhanmuseum.org/collection/artifact/dish-akm588

The Aga Khan Museum. (2017c). A year in review - Aga Khan Museum [print collateral].

Charitonos, K., Blake, C., Scanlon, E., \& Jones, A. (2012). Museum learning via social and mobile technologies: (How) can online interactions enhance the visitor experience? British Journal of Educational Technology, 43(5), 802-819. doi:10.1111/j.14678535.2012.01360.x

Dascalescu, D. (2016, August 23). Why "progressive web apps vs. native" is the wrong question to ask. Medium. Retrieved from https://medium.com/dev-channel/why-progressive-webapps-vs-native-is-the-wrong-question-to-ask-fb8555addcbb

Falk, J. H., \& Dierking, L. D. (2008). Enhancing visitor interaction and learning with mobile technologies. In L. Tallon \& K. Walker (Eds.), Digital technologies and the museum experience: Handheld guides and other media (pp. 19-33). USA: AltaMira Press.

McGonigal, J. (2011). Reality is broken: Why games make us better and how they can change the world. USA: The Penguin Press. 
Museum Hack - Renegade Tours. (2015, May 18). Engaging audiences workshop at the Basel Historical Museum [blog post]. Retrieved from https://museumhack.com/engagingaudiences-basel-historical-museum/

OJOO. (n.d.). 5 mobile solutions for museums [webpage]. Retrieved from http://www.ojoo.com/gamify-museums/

Parry, R. (2007). Recoding the museum: Digital heritage and the technologies of change. New York, NY: Routledge.

Sierzputowski, K. (2017, July 11). Text SFMOMA your favourite emoji and receive an artwork from their vast collection. Colossal. Retrieved from http://www.thisiscolossal.com/2017/07/text-sfmoma-your-favorite-emoji-and-receive-anartwork-from-their-vast-collection/

Simon, N. (2008). The participatory museum. Santa Cruz, CA: Museum 2.0.

Smith, J. K., \& Tinio, P. P. L. (2008). Audibly engaged: Talking the walk. In L. Tallon \& K. Walker (Eds.), Digital technologies and the museum experience: Handheld guides and other media (pp. 63-78). USA: AltaMira Press.

Srinivasan, R., Becvar, K. M., Boast, R., \& Enote, J. (2010). Diverse knowledges and contact zones within the digital museum. Science, Technology, \& Human Values, 35(5), 735-768. doi: $10.1177 / 0162243909357755$

Syms, Carly. (2017, June 7). The importance of scaffolding, storytelling, and the visitor experience (case study: The National Civil Rights Museum) [blog post]. Retrieved from https://museumhack.com/national-civil-rights-museum-case-study/ 
Tsai, H. \& Sung, K. (2012). Mobile applications and museum visitation. Computer, 45(4), 95-98.

vom Lehn, D., \& Heath, C. (2005). Accounting for new technology in museum exhibitions. International Journal of Arts Management, 7(3), 11-21.

Wood, E., \& Latham, K. F. (2014). The objects of experience: Transforming visitor-object encounters in museums. Walnut Creek, CA: Left Coast Press Inc. 